\title{
Development of Hygienic Urinal Device using Integrated Approach
}

\author{
A. Hambali ${ }^{1}$, A. H Firdaus ${ }^{2}$, Jaafar $\mathbf{R}^{3}$, R. Hambali ${ }^{4}$, M Effendi $^{5}$ \\ ${ }^{1-5}$ Faculty Kejuruteraan Pembuatan, Universiti Teknikal Malaysia Melaka, Malaysia \\ Hang Tuah Jaya, 76100 Durian Tunggal, Melaka, Malaysia. hambali@utem.edu.my
}

\begin{abstract}
This research presented the process of improving the existing hygienic urinal device using the integrated approach. Thus, various design activities have been involved in designing and fabricating the proposed product. The research aims to design and fabricate a new hygienic urinal device for solving the person who has difficulty accessing the toilet. The design process is based on the integrated method or Pugh's approach which includes various design activities such as market investigation, concept generation, concept selection, concept development and rapid prototyping concept. Investigating the existing similar product was carried out to ideate and generate the idea to improve the previous product. Analytical Hierarchy Process (AHP) and Technique for Order of Preference by Similarity to Ideal Solution (TOPSIS) were implemented to decide the best design concept during the selection process at the conceptual design stage. the best selected proposed design was fabricated using a 3D printer. The results showed that the improvement of the proposed new design which is $41 \%$ in terms of the number of parts, $2.05 \%$ in terms of fabrication time, $40 \%$ in terms of the number of operations, $11.8 \%$ in terms of weight reduction and $11.91 \%$ in terms of material cost reduction. This is showed that the proposed new design of the hygienic urinal device is much better compared to the existing design
\end{abstract}

Key words : Concept Selection, Design Process, Integrated Approach, Urinal Device

\section{INTRODUCTION}

Nowadays, the demand for social care services is increasing as the world also grew rapidly in development and technologies. Social care does not provide only medical care, but it includes countless social care services with health services in providing the nursing service [1]. The health care service in Malaysia is always changing towards excellent service as opposed to illness service due to the increase of the elderly population. One of the problems for the elderly is the facilities in accessing the toilet [2]. The urinal device is one of the best options to help the elderly to overcome the problems to go to the toilet. This research relates to urinal devices and more specifically to the personal urinal device that can be used by both male and female users. There are some innovations in size, configuration and angular orientation of the component that have been done but the function of each component is still the same. Until now, there are not many people who know about the product of urinal system that is easy, effectively and efficiently usable by both male and female users. From point of authors view many institutions such as hospitals, convalescent homes, nursing homes, and homes for a long time have a continuing need to separate urinals for males and females. The lack of a presently available and commercially satisfactory in the market about the universal urinal for both male and female users requires that these institutions expend the high cost of purchasing and storing two types of urinals. Table 1 shows several existing products that can be used by both male and female users.

Table 1: Existing urinal devices

\begin{tabular}{|l|c|c|c|c|}
\hline Type/features & $\begin{array}{c}\text { Uriwell } \\
\text { Urinal }\end{array}$ & $\begin{array}{c}\text { Spil-Pru } \\
\text { f Urinal }\end{array}$ & $\begin{array}{c}\text { Onedon } \\
\text { e Urinal }\end{array}$ & $\begin{array}{c}\text { Persona } \\
\text { 1 Urinal } \\
\text { Device }\end{array}$ \\
\hline Portable & $\sqrt{ }$ & $\sqrt{ }$ & $\sqrt{ }$ & $\sqrt{ }$ \\
\hline $\begin{array}{l}\text { For male and } \\
\text { female user }\end{array}$ & $\sqrt{ }$ & $\sqrt{ }$ & $\sqrt{ }$ & $\sqrt{ }$ \\
\hline Washable & $\sqrt{ }$ & $\sqrt{ }$ & $\sqrt{ }$ & $\sqrt{ }$ \\
\hline $\begin{array}{l}\text { Water spray } \\
\text { system }\end{array}$ & - & - & - & - \\
\hline $\begin{array}{l}\text { Water } \\
\text { container }\end{array}$ & - & - & - & - \\
\hline $\begin{array}{l}\text { Urine } \\
\text { container }\end{array}$ & $\sqrt{ }$ & $\sqrt{ }$ & $\sqrt{ }$ & $\sqrt{ }$ \\
\hline References & {$[3]$} & {$[4]$} & {$[5]$} & {$[6]$} \\
\hline
\end{tabular}

For the use of the Muslim community, it is required to use water for cleaning before performing the prayer. It means that part of water storage is required to consider in designing urinal device. According to a bathroom firm Bathstore survey, a man is using the toilet for one hour and 45 minutes a week (91 hours per year), while women spend their time using the toilet just one hour and 25 minutes a week, meaning that men spend more than 17 hours per year on the toilet compared to women [7]. Thus, it is important to design a portable urinal device that able to minimize the time spending in the toilet. 
Besides that, some problems caused the average age of men or women, or kids cannot run to the bathroom. Either it can be the situation of being stuck in traffic congestion or travel long distances on a highway without any exit.

Most of the people who travel for short or long distances with the car or other transport can end up with traffic congestion. The traffic jam caused mostly men will urinate on the side of the road or else they find themselves in pain or suffering the urge to urinate. It also can be even more difficult for the elderly population to access the toilet. The elderly population needs to have some difficulties go to the toilet due to health problems such as incontinence, overactive bladder or any other medical disorders. Lastly, the same problem also happens when old male or female people performing Hajj. Some of them have problems with their health and face difficulty going to the toilet and sometimes they need to wait for a long time to get it. To overcome this circumstance, there is important to come out with a new device that might assist related people who have difficulty accessing the toilet.

Many methods have been built and introduced to assist the designer to design and fabricate during the development process. The integrated method or Pugh's method is also well-known methods used in this research to design, develop and improve the product's design. Pugh's method includes customer demands, product design specification, conceptual design, detailed design, manufacture, and sale [9]. Despite some works have been carried out in terms of designing and fabricating products in the product development process but there is still very limited information or study the development of urinal device in the literature review. Thus, the paper illustrates the use of the integrated method in designing and fabricating by improving the existing design of the urinal device.

\section{METHODOLOGY}

The flow of research used in this paper is based on the Total Design approach as depicted in Figure 1. There are various design activities involved in this research such as concept generation, concept evaluation, concept development, improvement and fabrication.

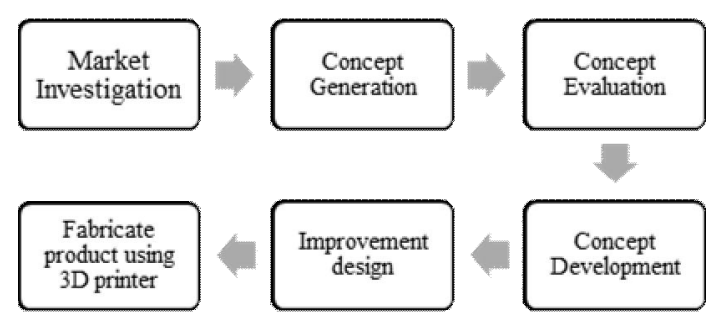

Figure 1: Design flow in this research
Overall design throughout its development as it starts from the market investigation and ends with the fabrication of prototyping of the product using 3D printer.

\subsection{Market Investigation}

The market is the initial step in the product development process and it is very important to determine the success of certain products. There are many products do not meet the customer's requirement that had been reported as an unsuccessful product [9]. This stage is important to implement to make sure that a better understanding of the customer's needs and requirements. There are more than 20 existing products had been explored in generating ideas of the development process.

\subsection{Concept Generation}

The design of the hygienic urinal system is achieved by identifying the problems surrounding the existing creation and generates ideas with a purpose to come out with the best design. Brainstorming is the most popular method for idea generation. The brainstorming method helps to gain ideas as much as possible as a wild idea is encouraged [10]. Some of the ideas that gain may be useless and cannot be used, but some ideas can be further developed into new concept development. There are five conceptual design of urinal devices were proposed as depicted in Figure 2
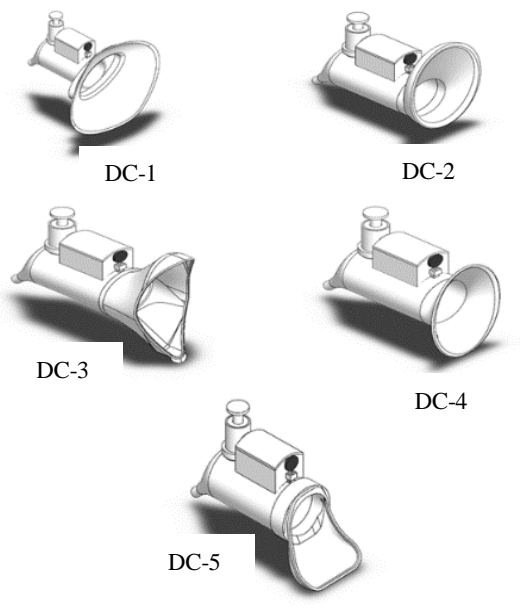

DC-4

Figure 2: Five different type of conceptual designs

\subsection{Concept Evaluation}

There were five design concepts of the hygienic urinal devices are proposed. The next step is mandatory to choose one of the best design concepts. The selection method to determine the best design concept is conducted by applying Analytic Hierarchy Process (AHP) $[11,12]$ and Technique for Order of Preference by Similarity to Ideal Solution (TOPSIS) [13] methods as shown in Figure 3. 
A. Hambali et al., International Journal of Emerging Trends in Engineering Research, 8(5), May 2020, 1716 - 1720

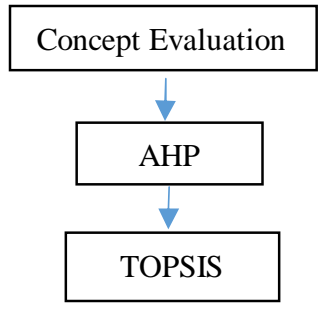

Figure 3: Selection process

From all AHP steps and calculations, Table 2 shows the priority vector of the main criteria.

Table 2: Priority vector of main criteria

\begin{tabular}{|c|c|}
\hline Size & 0.0819 \\
\hline Easy to Use & 0.1469 \\
\hline Style & 0.0389 \\
\hline Ergonomic & 0.2659 \\
\hline Shape & 0.46662 \\
\hline
\end{tabular}

TOPSIS method was used to determine the best design concept that meets the criteria among five-design concept. From the TOPSIS steps and calculation, design concept 3 showed the highest score which is 0.7362 as depicted in Table 3 . Therefore, this design concept 3 has been used to complete the next objective. The detailed design for this design concept was designed using SolidWorks software. TOPSIS method is very helpful in solving this problem because it helps to rank the five designs concept and select the best design among the five designs

Table 3: The rank of design selection

\begin{tabular}{|c|c|c|}
\hline $\begin{array}{c}\text { Design } \\
\text { concept (DC) }\end{array}$ & $\begin{array}{c}\text { Relative } \\
\text { Closeness (C+) }\end{array}$ & $\begin{array}{c}\text { Ran } \\
\mathrm{k}\end{array}$ \\
\hline DC-1 & 0.2805 & 5 \\
\hline DC-2 & 0.3449 & 3 \\
\hline DC-3 & 0.7362 & 1 \\
\hline DC-4 & 0.4384 & 2 \\
\hline DC-5 & 0.2886 & 4 \\
\hline
\end{tabular}

\subsection{Concept Development and improvement}

The concept selection revealed that concept design-3 is the best design which required further developments and improvement. For this purpose, the existing male design concept and the selected best female design (DC-3) were considered. The improvement of the design concept is starting from the combination between the existing design of male and proposed design of female user (DC-3) as shown in Figure 4.

\subsection{Fabricate the product using 3D printer}

The prototype of the proposed design was fabricated using the 3D printer machine as depicted in Figure 5. Prototype is important to be tested before the product going into full production as illustrated by Kim and Lim [14]. The process to create the 3D model from the FDM machine start from the 3D scanning data transfer into drawing and finally fabricate the model. The steps to fabricate the product using $3 \mathrm{~d}$ printer as follows: -

Step 1: Convert from 3D CAD to. STL file

Step 2: Support generation

Step 3: Model physical build-up

Step 4: Clean up and post

Step 5: Surface finishing

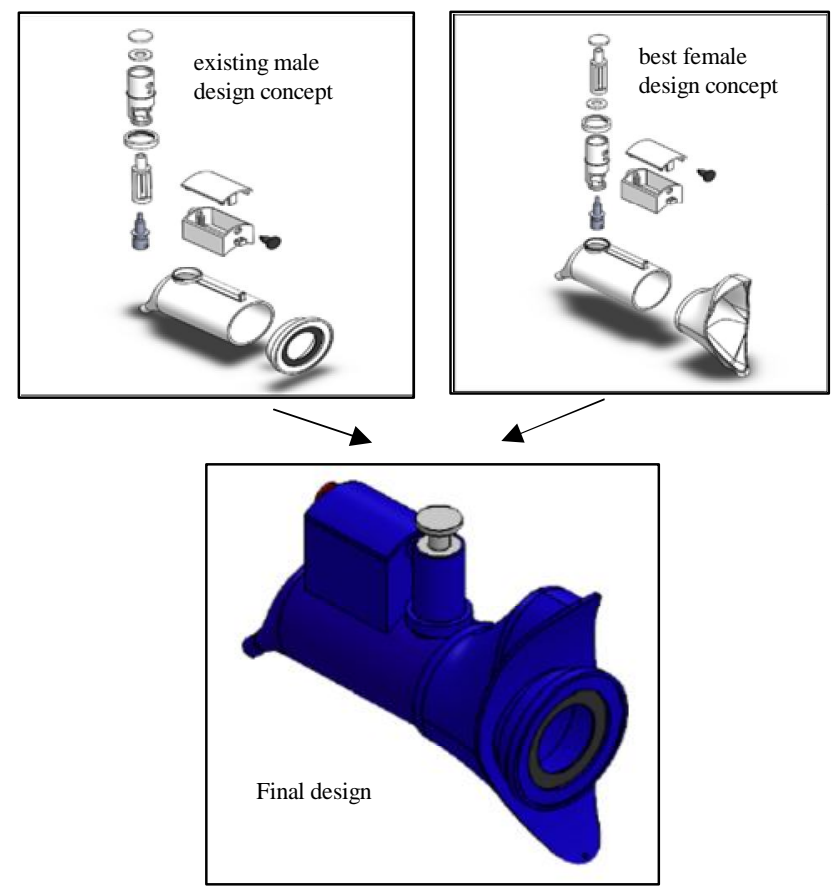

Figure 4: Development and improvement of the proposed design

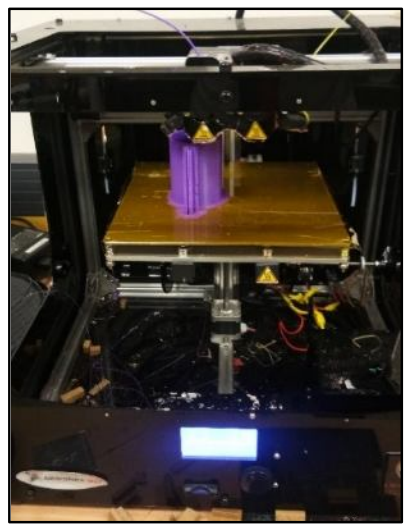

Figure 5: 3D printer 


\section{RESULTS AND DISCUSSION}

Figure 6 shows the final product and Table 4 shows the comparison between existing design and proposed new design.

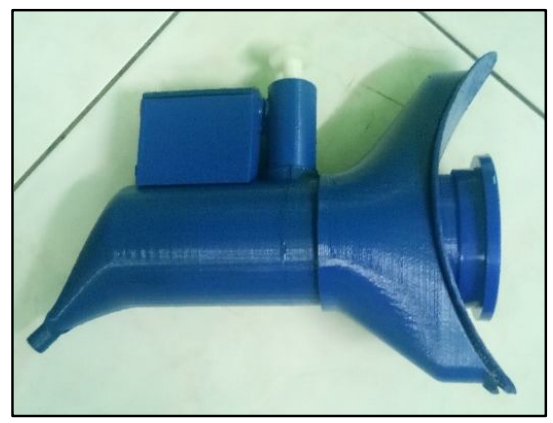

Figure 6: Proposed design of Hygienic Urinal System

Table 4: Percentage of improvement

\begin{tabular}{|c|c|c|c|}
\hline Elements & $\begin{array}{c}\text { Existing } \\
\text { design } \\
\text { (male and } \\
\text { female) }\end{array}$ & $\begin{array}{c}\text { Proposed } \\
\text { design }\end{array}$ & $\begin{array}{c}\text { Improveme } \\
\text { nt (\%) }\end{array}$ \\
\hline $\begin{array}{c}\text { Total } \\
\text { number of } \\
\text { parts }\end{array}$ & 22 & 13 & 41 \\
\hline $\begin{array}{c}\text { Total } \\
\text { fabrication } \\
\text { time using } \\
\text { 3D printer } \\
\text { (minute) }\end{array}$ & 1298.62 & 1271.96 & 2.05 \\
\hline $\begin{array}{c}\text { Total } \\
\text { number of } \\
\text { operations }\end{array}$ & 20 & 12 & 40 \\
\hline $\begin{array}{c}\text { Weight } \\
\text { (kg) }\end{array}$ & 0.51 & 0.45 & 11.8 \\
\hline $\begin{array}{c}\text { Total cost } \\
\text { of material }\end{array}$ & RM41.13 & RM36.23 & 11.91 \\
\hline
\end{tabular}

It shows clearly significant improvements in terms of the number of parts, fabrication time, number of operations, weight and material cost. In the existing design there were 24 different parts and in the proposed new design only 13 . This means that 9 parts have been eliminated which contributes to $41 \%$ improvement. It was also showed that design the number of operations was down from 20 to 12, the weight from 0.51 $\mathrm{kg}$ to $0.45 \mathrm{~kg}$, fabrication time from 1298.62 minutes to 1271.96 minutes and material cost from RM41.13 to RM36.23. In additional advantage of the new proposed design was a water spray system. This is important to make sure that water can reach the whole area of the private part of male and female. To determine the maximum distance of water can reach, the sample of testing was taken by pressing the spray system five times as depicted in Figure 7.

The result in Table 5 showed that the maximum average of the water distance was $200 \mathrm{~mm}$. It is showed that the proposed new design was function properly and sufficient to wash the area of the private part of male and female

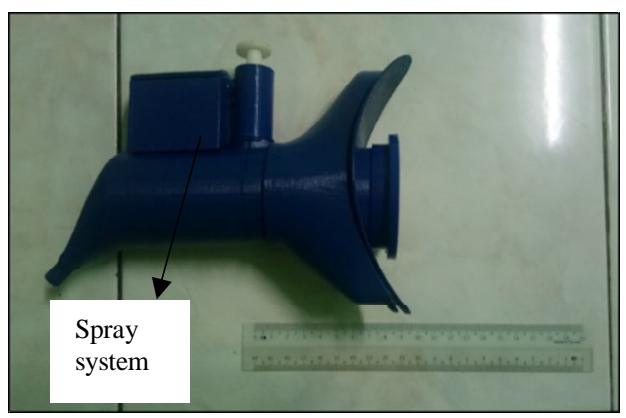

Figure 7: Testing of water distance

Table 5: Manual testing of the distance of the water spraying

\begin{tabular}{|c|c|}
\hline Press-test & Distance $(\mathrm{mm})$ \\
\hline Press no. 1 & $200 \mathrm{~mm}$ \\
\hline Press no. 2 & $200 \mathrm{~mm}$ \\
\hline Press no. 3 & $200 \mathrm{~mm}$ \\
\hline Press no. 4 & $200 \mathrm{~mm}$ \\
\hline Press no. 5 & $200 \mathrm{~mm}$ \\
\hline average & 200 \\
\hline
\end{tabular}

\section{CONCLUSION}

This paper discussed the design and development activities to produce the proposed new design of hygienic urinal system. Various design activities were involved such as market investigation, concept general, concept selection, concept development and improvement, and 3D prototyping product using 3D printer. Determining the right decision using a combination of AHP and TOPSIS was explored. The improvement of the proposed new design concept has conducted by combining the existing male design concept and selected female design concept and the result showed the significant advantages of the proposed new design. The improvement in terms of the number of parts, number of operations, weight, fabrication time and cost of material showed the advantages of the proposed new design compared to an existing design. The proposed new design product has also been tested in terms of the water spraying system and showed that the proposed new design better than the existing design in terms of its functionality and performance. 


\section{ACKNOWLEDGEMENTS}

Authors are grateful to Universiti Teknikal Malaysia Melaka (UTeM) and Ministry of High Education (MOHE) for financial support through MTUN commercialization grant scheme (MTUN/2019/FKP-COSSID/MC0001) awarded for the project.

\section{REFERENCES}

1. H. Hamimatulakmam, and S. Noralfishah. Social Care Facilities Management Benchmarking (SCfmB): Individual Accommodation for Residential Care Home for the Elderly (RCHfE) in Malaysia and United Kingdom. 1st FPTP Postgraduate Seminar 2013, pp. 1-5.

2. M. A. Abdel Salam, and A. K. Shams El-din. Developing smarter bathrooms for elderly and disabled people. Journal of Al-Azhar University Engineering Sector, vol. 14(52), pp. 1024-1035. 2019 https://doi.org/10.21608/auej.2019.42295

3. Saxondale. (2010, June 23). Uriwell unisex reusable personal leakproof portable toilet. Flexible retractable tube., 2018.

http://www.amazon.co.uk/reusablepersonalleakproofpo rtableretractable/dp/b0027mfa0e

4. Anaymonous. Spil-Pruf Portable Urinals for Men or Women. 2019.

https://www.rehabmart.com/product/spilpruf-urinals15945.html.

5. E. Kvarnström, and K. Emilsson. EcoSanRes Publications Series Urine Diversion: One Step Towards Sustainable Sanitation. Technical Report. Stockholm Environment Institute. 2006.

6]. P.E.K. Artis. Personal Urinal Device Useable by Males and Females. World Acad. Sci. Eng. Technol. Int. J. Mech. Aerosp. Ind. Mechatron. Manuf. Eng. Vol. 10, pp. 1040-1047, 1982.

7. H. Veidenbaum. Altering human behavior by design. Human's physiological urge to urinate in unexpected situations. M.S. Thesis. Department of Machinery. Tallinn University of Technology, Estonia. 2014.

8. S. Pugh. Integrated: Integrated Methods of Successful Product Engineering. Wokingham, England: Addison Wesley Limited. 1991. pp. 15-50.

9. L.A. Cooper. Research agenda to reduce risk in new product development through knowledge management: A practitioner's perspective. Journal of Engineering and Technological Management, vol. 20 (1-2), 117-140, 2003.

https://doi.org/10.1016/S0923-4748(03)00007-9

10. N. Bonnardel, and J. Didier. Brainstorming variants to favor creative design. Applied ergonomics, vol. 83, 102987, 2020.

https://doi.org/10.1016/j.apergo.2019.102987

11. X. Mi, M. Tang, H. Liao, H, W. Shen, and B. Lev. The state-of-the-art survey on integrations and applications of the best worst method in decision making: Why, what, what for and what's next?. Omega, vol. 87, pp. 205-225, 2019.

https://doi.org/10.1016/j.omega.2019.01.009

12. R.C. Gustilo, and C.C. Escolar-Jimenez,. An Analytic Hierarchy Process Approach in the Shortlisting of Job Candidates in Recruitment. International Journal of Emerging Trends in Engineering Research, vol. 7(9), 333-339, 2019. https://doi.org/10.30534/ijeter/2019/17792019

13. K.D. Prasad, K. V. Subbaiah, C.H. Gireesh, and U. Koushik. Evaluation of Conceptual Product Design Solutions using House of Quality-TOPSIS Integrated Methodology. International Journal of Mechanical Engineering (SSRG-IJME), pp. 206-212, 2017.

14. W. L. Kim and S. B. Lim. Smart Chair Cover for Posture Correction. International Journal of Emerging Trends in Engineering Research. Vol 7 (8), pp. 191-196, 2019.

https://doi.org/10.30534/ijeter/2019/14782019 